\title{
EL DERECHO DE PROPIEDAD PRIVADA COMO DERECHO NATURAL
}

\author{
HÉCTOR RIESLE \\ Profesor de Introducción al Derecho
}

S U M A R I O

Introducción. I. Naturaleza, derecho y ley. II. El derecho natural de propiedad privada. 1. Si es natural al hombre la posesión de los bienes exteriores: a) la naturaleza del ser humano. b) el orden intrínseco de la creación. 2. Si es conforme al orden natural que alguien posea bienes en privado. 3. Los textos pontificios. 4. La falsa tesis de la propiedad de lo suficiente y no de lo superfluo.

\section{N TRODUCCION}

Hemos dicho en otra ocasión ${ }^{1}$ que el derecho de propiedad privada es un derecho natural, un derecho que emana de la naturaleza humana, un derecho que forma parte de la ley natural. Estas denominaciones son ontologicamente idénticas, toda vez que la ley natural es la naturaleza humana en cuanto se la considera respecto a su orientación hacia su fin, Dios, y el derecho o los derechos naturales es o son el contenido de dicha ley². Cumple ahora probar el carácter natural del derecho de propiedad privada. Para ello, y en sintesis brevísima, expondremos los conceptos básicos sobre ley y derecho natural, para luego aplicarlos al derecho de propiedad privada.

\section{Naturaleza, Derecho, Ley}

Se llama ley, en su sentido más amplio y análogo, a la causa en cuanto

${ }^{2}$ Ver en esta Revista, No 15 (enero-junio, 1974), nuestro Derecho de pro. piedad privada, bien común y principio de subsidiaridad, 34-56, especialmente 45-49.

${ }^{2}$ Cabe hacer notar que el concepto de derecho natural, en su acepción estricta, es más restringido que el de la ley natural. Se llama derecho natural al contenido de la ley natural en cuanto dice relación con la justicia. La ley natural abarca en cambio toda la moral natural. 
genera su efecto. El orden universal está regido por la ley eterna, que es la propia razón divina en cuanto gobierna las cosas creadas. La participación de esta ley en las criaturas constituye la ley natural.

Mas, para hablar de ley natural, conviene esclarecer previamente el concepto de naturaleza. Se llama naturaleza a la esencia entendida como principio de operación. Y como sabemos que las operaciones siguen al ser, y el modo de operación al modo de ser, cada esencia tendrá un particular modo de operación tendiente a alcanzar su fin, pues todo ser opera por causa de un fin. A este particular modo de operación se llama legalidad, y es un principio que orienta los movimientos del ser a su fin.

Tenemos así que la ley es una especie de regla o medida que orienta las operaciones de un ser a su fin. $Y$ como hemos visto que la naturaleza es el principio que orienta las operaciones del ser, podemos decir que la ley natural es la naturaleza en cuanto principio orientador de sus movimientos.

Esta definición abarca la ley natural en sentido amplio. Hemos visto que a distintas naturalezas corresponden distintos modos de operación, lo que se puede expresar, respecto a la ley eterna, diciendo, que el modo de participación es conforme al modo de ser. Habría así, en principio, tantas leyes naturales como naturalezas. Pero aquí convienen algunas precisiones terminológicas que faciliten la comprension de los conceptos.

En sentido lato, se llama ley natural a la que corresponde a todas las criaturas en razón de su naturaleza. En sentido más estricto, es común al hombre y a los animales. En sentido propio y estricto corresponde al hombre. Conviene tener esto muy presente para evitar confusiones posteriores.

Conforme a las diversas naturalezas, serán diversas las respectivas leyes. Así, en los seres inanimados, la legalidad será automática y necesaria (leyes físicas y químicas), y en los animales será determinada e instintiva. En todos estos seres nos encontramos en el campo de la caùsalidad necesaria. En cambio en el hombre, ser racional y libre, su legalidad específica se conforma a su naturaleza Por ser ésta racional y libre, la ley no será determinada ni instintiva, sino conocida por la razón como buena, adecuada para alcanzar el fin del hombre; y no será automática y físicamente necesaria, sino libre y de necesidad moral. Por lo tanto, los incumplimientos y violaciones a la ley natural, antes 
de ser objeción a su existencia son confirmación de ella, pues demuestran su subordinación al modo de ser específico del ser humano, que es racional y libre. Es decir, la legalidad especifica del ser humano es una legalidad moral.

Santo Tomás precisa muy bien este diverso modo de participación al decir: "también los animales irracionales participan a su modo de la razón eterna, como la criatura racional. Pero la criatura racional participa intelectual y racionalmente de ella; por eso la participación de la ley eterna en la criatura racional se llama con propiedad ley, pues ley, como hemos dicho ya, es algo propio de la razón. Pero las criaturas irracionales no participan de este modo de la ley eterna; por eso sólo puede denominarse ley por cierta semejanza"3.

Así, la ley natural en sentido estricto sería lo mismo que la naturaleza humana en cuanto es regla o medida de sus actos. Pero hemos dicho que en el hombre esta ley es conocida por la razón. La ley natural se nos presenta así como un opus rationis, un producto de la razón, algo propio de ésta en cuanto regula y mide. En los otros seres no hay un principio activo y cognoscente, sino una participación ciega y pasiva de la ley eterna4.

Proprie et essentialiter, hemos visto, la ley natural se da en el hombre como un producto de la razón, como proposición imperativa. Son los enunciados o proposiciones primeras de la razón práctica, evidentes por sí mismos, y que sirven de materia o contenido propio a un hábito intelectual, la sindéresis: "se dice que la sindéresis es la ley de nuestro entendimiento, por cuanto es un hábito que contiene los preceptos de la ley natural, que son los primeros principios del orden moral"'s.

El derecho es el objeto de la justicia, en cuanto dictado por la inteligencia y la razón perfeccionadas por la sindéresis o la prudencia, que deben dictar los fines o los medios a las virtudes humanas de las facultades apetitivas. Y como la ley es el producto y creación propia de la sindéresis, en el caso de la ley natural, o de la prudencia gubernativa en el caso de la ley positiva, todo derecho objetivo debe estar informado por la ley como la materia por su forma, y ser conforme a ella; como dice Santo Tomás: "La ley no es el derecho mismo, propiamente ha-

Suma Teologica 1-2, q. 91, a. 2 ad 3.

${ }^{4}$ Cf. $1-2$, q. 90 , a. $1 ; 1.2$ q. 93 a. 5 ad c.

s1-2 q. 49, a. 1 ad 2. 
blando, sino cierta razón del derecho"6. Este producto (ley) se da en forma de proposiciones imperativas reguladoras de las acciones humanas al bien común, de toda la humanidad o de porciones determinadas de ella según el caso; estas proposiciones imperativas se enuncian en forma de un verbo mental compuesto del entendimiento o de la razón práctica, cuyo contenido es el derecho objetivo formalmente considerado, o, lo que es lo mismo, el justo medio, el objeto formal de la justicia?.

La ley natural arranca su obligatoriedad intrínseca de la naturaleza humana. Parece obvio que lo que ésta imponga será obligatorio para el hombre, pues lo intrínsecamente verdadero es intrínsecamente bueno, y por lo tanto obligatorio, por la conversión de los trascendentales. Pero así no llegaríamos aún a la fuente última de todo derecho.

Pues si la naturaleza tiene una legalidad intrínseca, que le es propia, la tiene por ser lo que es, por existir, y existe, y según su peculiar modo, por voluntad de Dios, Creador de todas las cosas. La naturaleza de una cosa es la idea concebida por la inteligencia Divina al crearla. Así, la fuente de la obligatoriedad de la ley natural se identifica con la fuente de todos los seres creados, Dios Eterno, Omnipotente, Omnisapiente y Creador.

Es decir, la fuente última de la obligatoriedad de la ley natural es la ley eterna. En el plano del orden moral, la ley eterna es la ley moral sicut in regulante et mensurante, y la ley natural lo será sicut in regulato et mensurato, como residiendo en el legislado, que es donde propiamente reside toda ley, en cuanto lo determina para orientarlo hacia su fin. Ley natural y ley eterna son realmente dos leyes, aunque una sea intrínseca y esencialmente dependiente de la otra. Se comprende así cuán acertada es la definición del Angélico al decir que: "la ley natural es la participación de la ley eterna en la criatura racional"8.

Esta ley natural constituye, en sus primeros principios, los contenidos en la sindéresis, inmutables, universales, evidentes por sí mismos, la fuente de toda otra ley humana. En sentido estrictísimo; la ley natural sólo está constituida por ellos. Esta sería la ley puramente natural. Luego el derecho puramente natural, formalmente considerado, es el

22-2 q. 57, a. 1 ad 2.

"Cf. Ramírez O. P., Santiago, El Derecho de Gentes, Madrid, Studium. 1955; y $1-2$, q. 90 , a. 1 ad $2 ; 1-2$, q. 94 a. 1 ad c.

${ }^{8} 1-2$, q. 91 , a. 2. 
contenido de esos primeros principios "In ipsa (humana intelligentia). est quidam habitus naturalis primorum principiorum operabilium quae sunt prima principia iuris naturalis qui quidem habitus ad synderesim pertinet" 9 . Luego, en sentido estrictísimo, toda ley que no esté formalmente inscrita en la sindéresis, en cuanto puesta por el hombre debe reputarse positiva. Pero el problema no es tan sencillo.

Si, como hemos visto, toda ley humana debe derivarse de la natural10 y dice León xirr: "Y las leyes civiles que cuando son justas, deducen su vigor de esa misma ley natural"'11 toda ley que se oponga a la ley natural será injusta, o una iniquidad ${ }^{12}$, pues su razón de ley es su derivación de la ley natural, resulta que debemos estudiar las formas, los modos, por los que las leyes humanas proceden de la ley natural; tal procedencia es de dos maneras: 1) en forma de conclusiones universales, y 2) en forma de simple determinación de los principios universalísimos o de las conclusiones universales. Por ejemplo, del principio de que se debe castigar a todo malhechor se deriva por simple determinación la cantidad y modo de la pena ${ }^{13}$. Este es el derecho puramente positivo, cuya materia propia es indiferente, cuya licitud depende de la ley puesta por autoridad competente, y cuya igualdad o ajustamiento depende de la libre voluntad de los contratantes en los convenios privados, o bien del arbitrio del legislador.

A su vez, el derecho derivado del natural a modo de conclusiones universales, participa de la naturaleza de éste, tiene algo de natural y algo de positivo, pues es esencialmente intermedio entre ambos y "medium oportet participare cum utroque extremorum"14, "medium enim debet esse affine utrique extremorum"1s de suerte que "utriusque sapiat extremi naturam"16, y por consiguiente "extrema inveniuntur in medio, quod participat utriusque naturam"17. Tal ley y derecho tienen

'De Veritate, 16, 1 c. Cf. ibld. ad 5 et 9.

${ }^{10}$ De Veritate, 16,1 c. Cf. ibid. ad 5 et 9.

${ }^{11}$ Enc. Rerum Novarum, Documentos Sociales, Biblioteca de Autores Cristianos. Madrid. 1959, 318.

${ }^{12} 1-2$, q. 95 , a. $2 ; 2-2$, q. 57 , a. 2 ad $2 ; 2-2$, q. 60 , a. 5 ad 1 et 2.

${ }^{13} 1-2$, q. 95, a. 2; in $V$ Ethic., lect. 12.

${ }^{14} \mathrm{De}$ spiritualibus creaturis, a. 3, arg. 3 sed contra.

${ }^{15}$ In I de Anima, lect. 7, num. 94.

${ }^{10}$ De mixtione elementorum. No 5, Opuscula Philosophica. Ed. J. Perrier, O. P., 22, París, 1949. Citado por S. Ramfrez, O. P., ob. cit.

${ }^{17}$ Ibid, paulo post. 
algo de natural, en la medida que participan de la ley y derecho natural su moralidad intrinseca y su fuerza obligatoria; y algo de positivo: el trabajo puesto por la razón que las deduce y las promulga ${ }^{18}$.

El medio participa de la naturaleza de los extremos y se puede reducir de alguna manera a ambos, como dice Santo Tomás: "Medium autem comparatum uni extremo, videtur alterum, in quantum participat naturam utriusque: sicut tepidum respectu calidi est frigidum, respectu vero frigidi est calidum"19, y como la ley y el derecho intermedio no están en un punto exactamente equidistante de los extremos, sino que, como en todas las cosas físicas y morales que versan sobre el ser móvil en cuanto tal, resulta toda una gama de participaciones, desde aquellas que participan casi totalmente de un extremo y muy poco del otro, hasta el caso opuesto, se deduce que las primeras conclusiones tienen mucho de ley natural y muy poco de ley positiva, mientras que las últimas participan muy poco de la ley natural y mucho de la positiva. Las primeras conclusiones, que tienen razón de principios respecto a las que las siguen, son fácilmente deducibles por todos los hombres, por rústicos que sean. Las últimas, que ya sólo tienen razón de conclusiones, salvo para la ley puramente positiva ${ }^{20}$, únicamente son deducibles por los hombres sabios y prudentes, con diligencia y sutileza. El derecho contenido en las primeras conclusiones se puede llamar derecho natural secundario. Igualmente se podría llamar terciario, etc., al contenido en las sucesivas conclusiones siguientes, pero no es necesario, porque se sobreentiende.

Este derecho natural secundario, cuando procede inmediatamente de la sindéresis, versa sobre los fines secundarios de nuestra naturaleza, que son, a su vez, medios intrínsecos y plenamente necesarios para alcanzar los fines primarios. Ahora bien, este derecho natural secuhdario, o derivado del primario a modo de conclusiones universales, inmediatas y necesarias, es lo que se ha llamado derecho de gentes.

Tal derecho, en cuanto participa de la ley natural, es decir de nues-

${ }^{19}$ Cf. S. Ramirez. O. P.; ob. cit., a la que hemos seguido de cerca.

${ }^{19} 1$, q. 108 , a. 5 ad 4.

${ }^{20}$ Es evidente que toda conclusión tiene razón de principio para cualquier conclusión posterior. Pero a las conclusiones primeras, que por su mayor universalidad y naturalidad son verdaderamente fuente y ralz inmediata de las conclusiones posteriones y más particularizadás, se les puede atribuir más propiamente razón de principio de las siguientes. 
tra naturaleza, es obligatorio. Su diferencia con el primario radica en que los juicios de la sindéresis, que corresponden al entendimiento y a la voluntad ut natura, son absolutos, y sin relación con ningún término medio 21 . Mientras que en el secundario, propio del intelecto y

${ }^{2 x}$ En relación con la clasificación del derecho natural en primario y secundario, según la doctrina de Santo Tomás, algunos consideran que el derecho primario sería sinónimo, por oposición al derecho de gentes, de legalidad genérica o animal, de instintividad. Se llega a decir que cuando Santo Tomás se refiere al derecho de gentes estaria usando como criterio diferenciador el mismo sentido puramente cosmológico que le da Ulpiano, por lo que constitui. ria un enclave ajeno a las líneas centrales de su pensamiento.

Cabe hacer notar, en primer lugar, que cuando Santo Tomás dice, según la fórmula de Ulpiano, que el derecho natural primario es común al hombre y a los animales, no se refiere a una identidad formal, sino sólo a una semejanza material. Ello es perfectamente claro en la 1-2, q. 94, a. 2 c., donde va explicando los contenidos de la ley natural que corresponden a cada una de las formalidades del ser del hombre. Pero si bien hay en el hombre distintas formalidades, hay una solà forma substancial, como en todo ser, que unifica el conjunto, y que en el hombre es el alma racional. Por ello, todos los contenidos de la ley natural, aunque materialmente correspondan a la formalidad de cosa o a la meramente animal, quedan esencialmente penetrados y englobados por la razón, que es la que les da su razón de ley en senti. do propio. Por ello la legalidad meramente instintiva o animal es formalmente distinta de la legalidad humana que recae sobre materias semejantes (co, mo, por ejemplo, la adecuación de los sexos o la alimentación de la prole).

En la 2-2, q. 57, a. 3, Santo Tomás plantea la diferencia entre derecho natural y de gentes. No significa con ello que el derecho de gentes no sea natural, sino que no es primaria y únicamente natural, pues supone un mínimo trabajo de la razón para concluirlo, por lo que se distingue, por oposición, del puramente natural, pues "el medio, en cuanto se compara a un extremo, parece el otro" (Vid. cita 19). Ambos, dice, proceden de la naturaleza, pero el primario lo hace considerando la cosa absolutamente y en sí misma, y en ello hay una semejanza puramente material, como hemos visto, con la legalidad animal, aunque sean formalmente distintas; el derecho de gentes, en cambio, se deduce considerando la cosa en relación a sus consecuencias. Como se ve, la fórmula de Ulpiano se excede a sí misma una vez integrada en el sistema tomista, y adquiere un sentido mucho más profundo. La diferen. cia entre derecho natural primario y derecho de gentes radica pues, para Santo Tomás, esencialmente en su distinto modo de procedencia de la naturaleza humana, lo que excluye considerar al derecho de gentes como una simple interpolación cosmológica en el sistema juridico tomista (aunque existan, por el orden de la Creación, paralelismos que revelan la unidad arquitectónica del conjunto).

Lo que sí ocurre es que como la consideración de la cosa en relación a sus consecuencias es propia de la naturaleza racional del hombre en cuanto 
de la voluntad ut ratio, es decir, como razonadora y discursiva, son comparativos y referidos a un término medio, por lo que son susceptibles de tener excepciones en casos concretos calificados y con justas causas referidas a su término medio. Pero ambos son intrínsecamente obligatorios, como pertenecientes al todo que es la ley natural.

\section{I1. El derecho natural de propiedad privada}

Habiendo hecho esta sumarísima exposición de la ley natural y sus derivados, entraremos a demostrar que el derecho de propiedad privada es un derecho natural. Tema es éste que ostenta particular relevancia, tanto en la historia universal como, más especificamente, en la historia de la Iglesia, pudiéndose encontrar en ella una estrecha ligazón entre la negación de tal derecho y múltiples herejías. Ya en el siglo in San Agustín refuta y ataca el comunismo de los varones apostólicos y de los pelagianos. En la Edad Media, la resurrección maniquea que significaron los valdenses y albigenses, negó también la propiedad privada. Lo mismo cabe decir de Wiclef y Juan Huss, precursores de la Reforma protestante. En la Revolución Francesa, eclosión sangrienta del naturalismo e iluminismo dieciochesco, aflora el movimiento comunista de Babeuf ${ }^{22}$. Al siglo xix le correspondió ver la aurora del socialismo, que ya condenó Pío rx en la Encíclica "Qui Pluribus" y en el "Syllabus". Desde entonces, todos los soberanos Pontífices han condenado no sólo el comunismo, sino las formas más mitigadas del socialismo, en la medida en que constituye un sistema materialista $y$ en que niegan el derecho de propiedad privada ${ }^{23}$.

racional, no pueden darse semejanzas con los animales ni siquiera en lo meramente material.

Sobre este tema puede consultarse la ya citada obra del padre Ramfrez, El Derecho de Gentes, y la intraducción a la 1-2 q. 94, del padre Carlos Soria, O.P., que aparece en la edición de la BAC de la Suma Teológica. ${ }^{22} \mathrm{Cf}$. Correa de Oliveira, Plinio, Revolución y Contrarrevolución, cap. vI, 1, 2, 3, 4. Santiago de Chile, Ediciones Paulinas, 1964.

${ }^{29}$ Pfo $_{1 \mathrm{x}}$, Enc. Nostis et Nobiscum, de 8 de diciembre de 1849; DS, 134; León XIII, Enc. Quod Apostolici Muneris, de 28 de diciembre de 1878; Diuturnum Illud, de 29 de junio de 1881, Documentos Políticos (BAC), 122; Humanum Genus, de 20 de abril de 1884, DP, 176; Libertas Praestantissimum, de 20 de junio de 1888, DP, 240; Rerum Novarum, de 15 de mayo de 1891 , DS, 312; Graves de Communi, de 18 de enero de 1901, DS, 422. Pío xI, Encs. 
Nos corresponde ahora probar que el derecho de propiedad privada es un derecho natural. Para hacerlo, seguiremos el orden de la argumentación que da Santo Tomás de Aquino (II-II, q. 66 a. 1; 2). Es decir, la adecuación que al respecto existe entre el orden de la creación y nuestra naturaleza racional y libre. El problema será planteado en dos fases: sí es natural al hombre la posesión de las cosas exteriores, y si es conforme al orden natural el que alguien posea una cosa privadamente.

\section{Si es natural al hombre la posesión de los bienes exteriores}

\section{a) La naturaleza del ser humano}

El hombre, hecho a imagen y semejanza de Dios, tiene un alma espiritual, por lo que está dotado de inteligencia y de voluntad. Por estar dotado de inteligencia y voluntad es señor de sus actos, es decir, es libre: "sólo la criatura racional tiene dominio đe sus actos, y se actúa libremente en sus operaciones"24. Por ser racional y libre, el hombre puede elegir las cosas que juzgue más a propósito para su propio bien y para la satisfacción de sus necesidades, como claramente sintetiza León xIII: "Pues el hombre, abarcando con su razón cosas innumerables, enlazando y relacionando las cosas futuras con las presentes y siendo dueño de sus actos, se gobierna a sí mismo con la previsión de sú inteligencia, sometido además a la ley eterna y bajo el poder de Dios; por lo cual tiene en su mano elegir las cosas que estime más convenientes para su voluntad, no sólo en cuanto al presente sino también para el futuro. De donde se sigue la necesidad de que se halle en el hombre el dominio no sólo de los frutos terrenales, sino también el de la tierra misma, pues ve que de la fecundidad de la tierra le son proporcionadas las cosas necesarias para el futuro"25. Ahora, este dominio del hombre sobre los bienes exteriores lo es en cuanto a su uso "quantum ad usum ipsius rei"26. Ya que en cuanto a su naturaleza

Quadragesimo Anno, de 15 de mayo de 1931, DS, 693; Divini Redemptoris, DP, 669. Plo xII, Aloc. La Solemnita, de 10 de junio de 1941, DS, 952; Mens. radiof. Oggi, de $1^{\circ}$ de septiembre de 1944 , DS, 983. Juan xxiI, Enc. Mater $e t$ Magistra, 34, y muchísimos otros textos.

${ }^{24}$ Suma contra los gentiles, Libro III, Capitulo 111.

${ }^{20}$ Rerum Novarum, 5, DS, 315.

$202-2$, q. 66 , a. 1, c. 
"quantum ad eius naturam" las cosas dependen sólo de Dios, pues de El reciben el ser.

\section{b) El orden intrinseco de la creación}

Las criaturas no sólo coexisten, sino que forman un orden. "Es justo que todas las cosas sean ordenadisimas" dice San Agustín, y Santo Tomás agrega: "la creación está animada por un orden intrínseco que se orienta a un fin"27. Según este orden, los seres más imperfectos existen para los más perfectos 28 . "En el orden de las cosas las imperfectas existen para las perfectas, las plantas existen en general para los animales y los animales para el hombre" 29. "...Tiene el hombre el dominio natural de las cosas exteriores, ya que, como hechas para él, puede usar de ellas mediante su razón y voluntad en propia utilidad, porque siempre los seres más imperfectos existen para los más perfectos, como se ha expuesto anteriormente; y con este razonamiento prueba Aristóteles que la posesión de las cosas exteriores es natural al hombre"30. Luego, por una parte, las cosas exteriores están ordenadas al hombre y, por otra, éste tiene capacidad natural de ejercer dominio sobre ellas para su propia utilidad, in proprium commodum. De este encuentro de términos recíprocamente adecuados nace una relación que, si el dominio es pleno o perfecto, es el derecho de propiedad.

De lo expuesto podemos concluir que es natural al hombre la posesión de los bienes exteriores.

2. Si es conforme al orden natural que alguien posea bienes en privado

Hemos visto que el hombre tiene dominio sobre las cosas materiales creadas, y que éstas están ordenadas a él. Pero el problema que ahora nos preocupa es la forma de ejercicio actual de esa capacidad de dominio. Para resolverlo hemos de ver cuáles son las posibles soluciones alternativas, para luego determinar cuál es la verdadera y adecuada. Y el problema, como lo hace notar el R. P. Téfilo Urdanoz O. P.,

\section{st Suma Contra Gentiles, Libro 3, Cap, 112.}

282-2, q. 66, a. 1, c.

$202-2$, q. 64 , a. 1, c.

$202-2$, q. 66 , a. 1 , c. 
en su comentario a la Summa Theologica ${ }^{31}$ oscila forzosamente entre la propiedad privada y la posesión común de los bienes o comunismo. Las otras soluciones participan de una y de otra, como todo medio participa de los extremos. Pero como no se trata de buscar eclecticismos, debemos hallar una verdadera solución al problema de acuerdo a la naturaleza de las cosas. Esta antinomia es antigua: ya Aristóteles refuta en su Politica el comunismo de Phaleas de Calcedonia, Hippodamus de Milețo y el de Platón, enunciado en la República.

El principal argumento que se ha dado en pro del comunismo de bienes es aquel basado en que el derecho natural señala primariamente que la capacidad de dominio está inscrita en todas las personas humanas sin excepción de nadie, y que los bienes exteriores están para el uso de todos los hombres. Entre quienes sostienen esto, existen dos posiciones: la de los que miran como ilícita a la propiedad privada, y cuya refutación nos dispensamos, pues como hace notar el $R$. $P$. Teófilo Urdanoz O. P. en su Introducción a la II-Ir, q. 66, la licitud intrinseca de la propiedad privada es de fe católica ${ }^{32}$, y la de los que opinan que la ley natural es meramente permisiva, pero no preceptiva, respecto a la propiedad privada.

Cumple ahora probar que el derecho de propiedad privada no sólo está permitido, sino preceptuado por la ley natural. Dice Santo Tomás de Aquino: "todas aquellas cosas hacia las cuales siente inclinación natural el hombre pertenecen a la ley natural, entre las cuales propia del hombre es su inclinación a obrar segứn el dictamen de la razón"33, y siendo el modo de participación conforme al modo de seri4, el hombre es naturalmente inclinado a extraer de los principios de la sindéresis las conclusiones que con más precisión lo guíen en las circunstancias concretas. Las que son extraídas de modo fácil, inmediato y necesario, hemos visto que participan casi totalmente de la ley natural, teniendo de positivo sólo el trabajo puesto por la razón para deducirlas, que en este caso es mínimo. De manera que la observación de la naturaleza humana lleva a la razón a concluir que la propiedad privada

siUrdanoz, O. P., Teófilo, Introducción a la q. 66 de la $2-2$ de la Suma Teológica de Santo Tomás de Aquino; en Suma Teológica, BAC, Madrid, 1956, Tomo vill.

s2Ibid., 481.

391-2, q. 94, a. 4, c.

${ }^{34} 1-2$, q. 91 , a. 3 , ad 3. 
es necesaria, como dice el Angélico: "Es lícito que el hombre posea cosas propias, y es también necesario a la vida humana por tres motivos: primero, porque cada uno es más solícito en la gestión de aquello que con exclusividad le pertenecé que en lo que es común a todos o a muchos, pues cada cual huyendo del trabajo deja a otro el cuidado de lo que conviene al bien común, como sucede cuando hay muchedumbre de servidores; segundo, porque se administran más ordenadamente las cosas humanas cuando a cada uno incumbe el cuidado de sus propios intereses, mientras que reinaría la confusión si cada cual se cuidara de todo indistintamente, y tercero, porque el estado de paz entre los hombres se conserva mejor si cada uno está contento con lo suyo, por lo cual vemos que entre quienes en común y proindiviso poseen algo surgen más frecuentemente contiendas"35. Así pues, el hombre, al seguir su inclinación natural de conducirse según el dictamen de la razón al aplicarla a su propia naturaleza, deduce que la propiedad privada es necesaria para la mayor diligencia, orden y paz entre los hombres. Tal conclusión, como emanada de su naturaleza, es inmutable e intrínsecamente obligatoria, lo que basta para demostrar que el derecho de propiedad privada está preceptuado por la ley natural. Es un precepto de derecho de gentes, es decir, natural secundario derivado del primario a modo de conclusiones universales, Inmediatass y necesarias, que justamente por proceder de la inteligencia $u t$ ratio ha sido llamado el derecho natural especificamente humano o racional, pues el hombre participa de él según lo que le es especifico: su razón.

Por ser un precepto secundario de la ley natural puede sufrir ciertas excepciones, sea por la prioridad de un precepto primario, sea por una justa causa referida a su término medio, que en este caso es diligencia, orden y paz entre los hombres, o, más sucintamente, bien común.

La propiedad tiene relaciones muy estrechas con la libertad. El hombre es, como corolario de su naturaleza racional, libre; es decir, señor de sí, pues la libertad es el acto de autoposesión; es también dueño de sus actos (a ellos mira específicamente la libertad humana, pues en cuanto a su naturaleza el Señor es Dios. La libertad se define como acto). Este dominio del hombre sobre sus actos es absolutamente individual, pues no procede en modo alguno de la sociedad. Yo soy dueño de mí, con o sin sociedad. Esto en cuanto a la procedencia, pues

$$
852-2 \text {, q. 66, a. 2, c. }
$$


es evidente que en sociedad los actos del hombre son ordenados por el bien común, lo que no es en modo alguno violación de su libertad, pues tanto como el hombre es dueño de sí está naturalmente inclinado a conducirse según el dictamen de su razón, y ésta le indica ordenarse y adecuarse al bien común. Es decir, el hombre como individuo es libre, pero su naturaleza sociable le impone la convivencia social y la ordenación de sus actos al bien común.

Nos corresponde demostrar que los actos del hombre son la fuente del derecho de propiedad. Este, al apropiarse de una cosa exterior nullius, ordenada a él como toda cosa exterior, constituye, con un acto de su voluntad libre, la relación estable llamada propiedad o dominio, al actualizar sobre un objeto adecuado la potencia de dominio inscrita en su naturaleza. Y no hay manera de soslayar el carácter de natural de esta apropiación individual, pues aparte de realizarse ya antes de la existencia de la sociedad civil, sus dos términos son naturales: una cosa exterior naturalmente ordenada al hombre como a su fin y la capacidad natural del hombre para apropiarse de ella. Siendo naturales los dos elementos de la relación y al estar recíprocamente adecuados, no hay más remedio que reconocer a la relación misma carácter de natural. Se podria contraargumentar que, tanto como hay apropiación individual, puede haberla colectiva por acuerdo de las partes o decisión de la sociedad. Pero ello no quita nada a nuestro argumento, pues si es por acuerdo de las partes no hay problema, ya que es la misma libertad humana la que es causa del pacto. $Y$ si es por imposición de la sociedad tampoco vale el argumento, pues primero está el hombre que la sociedad por lo tanto la forma normal de apropiación será siempre individual, teniendo la de la sociedad, siempre, carácter subsidiario en cuanto exigida por el bien común. Serfá, además, imposible que la autoridad impusiera la apropiación común como norma general, pues no está la sociedad para mutilar la naturaleza humana, sino para perfeccionarla, y la ley positiva no puede derogar la natural.

Y esto, que se ve tan claro en la apropiación de una cosa nullius, se ve aún más claro en el trabajo humano. El hombre, como señor de sus actos, es dueño de su trabajo. Luego es libre para contratarlo con otro, dándolo a cambio de un salario justo. Lo que el hombre recibe por su trabajo es, entonces, la retribución justa de sus actos, es decir, su trabajo hecho dinero o especies. Luego, es dueño y señor de éstas, para consumirlas o ahorrarlas. Aquí está ya la propiedad 
privada individual perfecta. Pero como señor y dueño puede disponer de ellas y trocarlas por, verbigracia, un campo. Este campo no es otra cosa que el salario, es decir el trabajo, o, lo que es lo mismo, los actos propios de un serr libre, revestidos de otra apariencia.

Asi, por la vía del trabajo, algo tan propio e individual como son los actos del hombre revisten la forma de propiedad. $Y$ tanto como el hombre en la vida en sociedad (en cuanto se refiere a la justicia) dispone de sus actos para si, sin otras limitaciones que el derecho ajeno y el bien común, el derecho de propiedad, que es consecuencia de estos actos, participa de tales caracteristicas.

Luego, la propiedad es un derecho individual, al cual le es inherente una función social en cuanto ha de estar orientado hacia el bien común. Se puede, pues, decir que según su naturaleza la propiedad es un derecho individual en la misma medida en que los actos del hombre pertenecen a éste, y tiene una función social en la misma medida en que los actos del hombre han de estar orientados hacia el bien común.

Lo mismo cabe decir del trabajo aplicado a una cosa nullius, pues resultan sobreañadidas las razones. El hombre se hace dueño de la cosa por ocupación e incorpora a ella algo tan propio como su trabajo. Se puede decir que es doblemente dueño. Si la cosa se ha adquirido por un título derivativo ocurre lo mismo. Si es ajena nace una forma de copropiedad, pues coexisten en la cosa el dominio de su dueño y el trabajo incorporado. Pero aquí hay que distinguir según la forma de incorporación del trabajo, pues si ésta se ha hecho en forma que no tenga consecuencias permanentes, como una siembra en suelo ajeno, resulta que la copropiedad se referirá a los frutos, que serán en parte del dueño del suelo y en parte del autor de la siembra, y no al suelo. Mientras que si se trata de una especificación, como si alguien con el bronce ajeno hace una estatua, hay copropiedad sobre la cosa misma. Es evidente que en esta materia hay amplio campo para la reglamentación positiva, que no nos corresponde tratar.

Y si el hombre se hace duéro de algo, puede disponer de ello, gratuitamente o a cambio de algo, durante su vida o para después de ella, de cualquier modo lícito, de donde nace la validez de lo adquírido por los títulos derivativos de dominio, inter vivos o mortis causa; y siempre es causa la libertad humana.

Así se comprenden las palabras de Pío xII cuando dice "sólo quien 
rehúse al hombre esta dignidad de persona libre puede admitir la posibilidad de sustituir el derecho a la propiedad privada ( $y$, por consiguiente, la propiedad privada misma) por un vago sistema de seguridades o garantias legales de derecho público"' 36 .

\section{Los textos pontificios}

Nos corresponde ahora repetir el camino apoyados en la autoridad de los Sumos Pontífices. Citaremos, en primer lugar, algunos de los muchísimos textos que declaran que la propiedad privada es un derecho natural. Dice S. S. León xirr en la Encíclica Quod Apostolici Muneris: "La Iglesia manda, además, que el derecho de propiedad nacido de la misma naturaleza sea mantenido intacto e inviolado en manos de quien lo posee"37. Y en la Rerum Novarum 38 agrega: "Pero lo que todavía es más grave, proponen un remedio en pugna abierta con la justicia, en cuanto que el poseer algo en privado como propio es un derecho dado al hombre por la naturaleza".

San Pío x sintetiza la doctrina de la Rerum Novarum al decir: "Es derecho de naturaleza sin excepción, la propiedad privada, fruto del trabajo o del ingenio, o por cesión o donación de otro; y cada uno puede razonablemente disponer de él como le parezca"39. Pío xI reafirma que "por la naturaleza o por el Creador mismo se ha concedido al hombre el derecho de dominio privado"40. Y Pío xIr agrega: "La Iglesia ha reconocido siempre el derecho natural de propiedad y la transmisión hereditaria de los bienes propios" 41 .

Finalmente Juan xxin dice en Mater et Magistra: "Esa duda carece en absoluto de fundamento. Porque el derecho de propiedad privada, aún en lo tocante a bienes de producción, tiene un valor permanente, ya que es un derecho contenido en la misma naturaleza, la cual nos

${ }^{9}$ Pio xII, Soyez les bienvenus, Discurso a los Miembros del Instituto Internacional para la Unificación del Derecho Privado, 20 de mayo de 1948, D. Juridicos, 269.

${ }^{37 D S}, 188$.

${ }^{39 D S}, 314$.

${ }^{30}$ Motu proprio Fin dalla prima Nostra Enciclica, sobre la Acción Popular Cristiana, DS, 464.

${ }^{40}$ Enc. Quadragesimo Anno, 45, DS, 713.

“Mens. radiof. Oggi de 10 de septiembre de 1944 , citando la Quadragesimo Anno, DS, 983. 
enseña la prioridad del hombre individual sobre la sociedad civil, y por consiguiente la necesaria subordinación teleológica de la sociedad civil al hombre"42.

Sentado que en el pensamiento pontificio la propiedad privada es un derecho natural, nos corresponde ver las razones que, desde su autoridad, dan los Pontífices para considerarla como tal. Para ello seguiremos el mismo plan trazado en la fundamentación por vía filosófica de la propiedad privada como derecho natural. Es decir, nos referiremos, primero, a si es natural al hombre la posesión de los bienes exteriores, analizando esto desde el punto de vista de la naturaleza humana y del orden intrínseco de la creación, para luego estudiar si es lícito a alguien poseer una cosa como propia.

3.1. Si es natural al hombre la posesión de los bienes exteriores

a) La naturaleza del ser humano

Pío XII nos dice: "Todo hombre, por ser viviente dotado de razón, tiene efectivamente el derecho natural y fundamental de usar de los bienes materiales de la tierra 43 ".

b) El orden intrinseco de la creación

"Porque el Creador y Gobernador de todas las cosas las ha dispuesto con su providente sabiduria de tal manera que las cosas infimas alcancen sus fines respectivos a través de las intermedias, y las intermedias a través de las superiores" 44 . "La naturaleza animal, por elevada que sea la medida en que se la posea, dista tanto de contener y abarcar en sí la naturaleza humana, que es muy inferior a ella y nacida para servirla y obedecerla"45. El que Dios haya dado la tierra para usufructuarla y disfrutarla a la totalidad del género humano, no puede oponerse en modo alguno a la propiedad privada 46 .

De estas citas se deduce con evidencia que, según los Documentos

${ }^{42} \mathrm{NO} 109$.

${ }^{43}$ Disc. La solemnitá, de 19 de junio de 1941, DS, 956.

${ }^{4}$ Enc. Quod A postolici Muneris, DP, 67.

4Lén XIr, Rerum Novarum, DS, 314.

4 Ibid., 316. 
del Supremo Magisterio, es natural al hombre la posesión de los bienes exteriores, pues tanto la naturaleza humana como la de los bienes exteriores, se encuentran recíprocamente ordenadas y adecuadas.

3.2. Si es conforme al orden natural que alguien posea una cosa como propia

Como hemos visto, éste es el problema de las formas de ejercer la propiedad. La alternativa que se plantea entre propiedad privada y posesión común, ha sido zanjada terminantemente por los Papas. Ya Plo Ix dice, en la Encíclica Qui Pluribus: "Entre éstos, esa abominable y sobre todas antirracional doctrina llamada del comunismo, que, de admitirla, acabará por destruir desde sus cimientos las cosas y las propiedades de todos y hasta la misma sociedad humana"47. León XIII agrega: "Seducidos (los socialistas), finalmente por la codicia de los bienes terrenos que es la raiz de todos los males y, por la que; al dejarse llevar de ella muchos se extraviaron en la fe, atacan el derecho de propiedad sancionado por la ley natural; y con un monstruoso atentado, aparentando atender a las necesidades de todos los hombres y pretextando satisfacer los deseos de éstos, se esfuerzan por arrebatar, para convertirlo en propiedad común, todo lo que se adquiere a título de legitima herencia, o por el trabajo intelectual o manual o con el ahorro personal48".

La propiedad como fruto del trabajo es muy bien precisada por León XiIr. "Sin duda alguna, como es fácil de ver, la razón misma del trabajo que aportan los que se ocupan de algún oficio lucrativo y el fin primordial que busca el obrero es procurarse algo para sí y poseer con propio derecho una cosa como suya. Si, por consiguiente, presta sus fuerzas o su habilidad a otro, lo hará por esta razón: para conseguir lo necesario para la comida y el vestido; y por ello, merced al trabajo aportado, adquiere un verdadero $y$ perfecto derecho no sólo a exigir el salario sino también a emplearlo a su gusto. Luego, si, reduciendo sus gastos, ahorra algo e invierte el fruto de sus ahorros en una finca; con lo que puede asegurarse más su manutención, esta finca no es realmente otra cosa que el mismo salario revestido de

"DS, 79.

${ }^{4}$ QAM, DP, 62. 
otra apariencia, y de ahí que la finca adquirida por el obrero en esta forma debe ser tan de su dominio como el salario ganado con su trabajo. Ahora bien, es en esto precisamente en lo que consiste, como fácilmente se colige, la propiedad de las cosas, tanto muebles como inmuebles. Luego los socialistas empeoran la situación de los obreros todos, en cuanto tratan de transferir los bienes de los particulares a la comunidad, puesto que, privándolos de la libertad de colocar sus beneficios, con ello mismo los despojan de la esperanza y de la facultad de aumentar los bienes familiares y de procurarse utilidades" 49 .

Respecto al argumento de los partidarios de la comunidad de bienes que pretende fundamentarla en el hecho de que la capacidad de dominio está inscrita en todos los hombres, lo que es cierto, y en la destinación de los bienes exteriores al uso de toda la humanidad, los Papas lo rechazan categóricamente: "Pero, lo que todavía es más grave, proponen un remedio en pugna abierta contra la justicia, en cuanto que el poseer algo en privado como propio es un derecho dado al hombre por la naturaleza. En efecto, también en esto es grande la diferencia entre el hombre y el género animal. Las bestias, indudablemente, no se gobiernan a sí mismas, sino que lo son por un doble instinto natural, que ya mantiene en ellas despierta la facultad de obrar y desarrolla sus fuerzas oportunamente, ya provoca y determina, a su vez, cada uno de sus movimientos. Uno de esos instintos los impulsa a la conservación de sí mismos y a la defensa de la propia vida; el otro a la conservación de la especie. Ambas cosas se consiguen, sin embargo, fácilmente con el uso de las cosas al alcance inmediato, y no podrian ciertamente ir más allá, puesto que son movidas sólo por el sentido y por la percepción de las cosas singulares. Muy otra es, en cambio, la naturaleza del hombre. Comprende simultáneamente la fuerza toda y perfecta de la naturaleza animal, siéndole concedido por esta parte, y desde luego en no menor grado que el resto de los animales, el disfrute de los biennes de las cosas corporales. La naturaleza animal, sin embargo, por élevada que sea la medida en que se la posea, dista tanto de contener en si la naturaleza humana, que es muy inferior a ella, y nacida para servirla y obedecerla. Lo que se acusa y sobresale en nosotros, lo que da al hombre el que lo sea y se distinga de las bestias, es la razón e inteligencia. Y por esta causa de que es el único animal dotado de razón es de necesidad conceder al hombre ${ }^{48}$ RN, DS, 313-314. 
nio 8610 el uso de los bienes, cosa común a todos los animales, sino tambien el poseerlos con derecho estable y permanente, y tanto los bienes que se consumen con el uso cuanto los que, pese al uso que se hatee de ellos, perduran" 50 .

El texto que hemos transcrito es muy claro: anuncia en primer lugar que el poseer algo en privado como propio es un derecho dado al hombre por la naturaleza. Para fundamentar tal afirmación analiza la diferencia que hay entre la naturaleza animal y la naturaleza humana, y concluye que por ser el hombre un animal dotado de razón, es de necesidad concederle no sólo el uso de los bienes, sino también el poseerlos con derecho estable y permanente.

Pero este derecho estable y permanente tiene como sujeto de inherencia al hombre, $Y$ el hombre no es un mero concepto ni una abstracción descarnada aplicable a una especie. Propiamente el hombre existe como personas o individuos humanos, que son los titulares propios de los derechos. Luego, las características de un derecho exigido por la naturaleza humana deben darse, fundamentalmente, en cuanto tal derecho se vincula a un hombre concreto. De donde se deduce que esta estabilidad y permanencia en la posesión de los bienes exteriores debe darse en la posesión que los individuos humanos ${ }^{\sigma 1}$ concretos tengan de los bienes exteriores. Queda asi excluida la comunidad de bienes como forma normal de organización económico-social, pues en ello la estabilidad y la permanencia no se radican en el individuo titular del dominio sobre una cosa, siquiera en principio, sino que quedan en total dependencia del arbitrio de la autoridad.

A idéntica conclusión nos lleva un análisis meramente formal del texto citado de la Rerum Novarum, pues en él la referencia a la necesidad de dar al hombre estabilidad y permanencia en el dominio de los bienes exteriores se plantea como fundamento de la afirmación de que poseer algo en privado como propio es un derecho dado al hombre por la naturaleza, y de la condenación del socialismo en cuanto propicia la comunidad de bienes. Luego, en el pensamiento de León xIIr, comunidad de bienes como forma normal de apropiación y estabilidad y permanencia en el dominio del hombre sobre los bienes exteriores, aparecen como proposiciones contradictorias. $\mathrm{Y}$ ello, justamente

* RN, DS, 314-315.

-Consideramos, a la inversa de Maritain, que no cabe distinción entre individuo humano y persona humana. 
por el supuesto, implícito pero importantísimo, de que ese hombre titular del derecho no es una mera abstracción, un ente de razón, sino que un individuo real y concretamente existente.

Este derecho estable y permanente, nos dice el Pontífice, abarca "tanto los bienes que se consumen por el uso cuanto los que, pese al uso que se hace de ellos, perduran"52, pues es propio del hombre prever sus necesidades futuras, y organizar los recursos de que dispone para poder satisfacerlas en la mejor forma posible. Dentro de los bienes que no se consumen por el uso quedan comprendidos conceptualmente, a falta de distinción expresa de los Pontífices, los bienes de producción. Mas, por si restare alguna duda, han resuelto concretamente el punto: "Esto resalta todavía más claro cuando se estudia en sí misma la naturaleza del hombre. Pues el hombre, abarcando con su razón cosas innumerables, enlazando y relacionando las cosas futuras con las presentes y siendo dueño de sus actos, se gobierna a sí mismo con la previsión de su inteligencia, sometida además a la ley eterna y bajo el poder de Dios; por lo cual tiene en su mano elégir las cosas que estima más convenientes para su bienestar, no sólo en cuanto al presente, sino también para el futuro. De donde sè sigue la necesidad de que se halle en el hombre el dominio no sólo de los frutos terrenales, sino también el de la tierra misma, pues ve que de la fecundidad de la tierra le son proporcionadas las cosas necesarias para el futuro. Las necesidades de cada hombre se repiten de una manera constante; de modo que, satisfechas hoy, exigen nuevas cosas para mañana. Por tanto, la naturaleza tiene que haber dotado al hombre de algo estable y perpetuamente duradero, de que pueda esperar la continuidad del socorro. Ahora bien, esta continuidad no puede garantizarla más que la tierra con su fertilidad"'53.

Con la cita transcrita queda incluido como objeto del derecho natural de propiedad privada el bien de producción por antonomasia: la tierra. Y S. S. Juan XxiII nos dice en su inmortal Encíclica Mater et Magistra: "Esta duda carecè en absoluto de fundamento. Porque el derecho de propiedad privada, aún en lo tocante a bienes de producctón, tiene valor permanente, ya que es un derecho contenido en la misma naturaleza, la cual nos enseña la prioridad del hombre indi-

${ }^{52 V i d . ~ F e r n a ́ n d e z ~ C o n c h a, ~ R a f a e l, ~ D e r e c h o ~ N a t u r a l, ~(2 ~ v o l .) ~ S a n t i a g o ~ d e ~}$ Chile. El Correo, 1881. Tomo Ir, 53.

${ }^{{ }^{3}}{ }_{\text {León }} \mathrm{xII}, \mathrm{RN}, \mathrm{DS}, 315$. 
vidual sobre la sociedad civil, y, por consiguiente, la necesaria subordinación teleológica de la sociedad civil al hombre"'54. Con esto no resta duda posible.

4. Extensión del derecho natural de propiedad privada en cuanto a la cantidad y valor de los bienes

Antes de terminar quisiéramos tocar, siquiera de paso, la tesis, que hoy se ha vulgarizado en forma apreciable, de que el derecho natural respaldaria como legítima "la propiedad de lo suficiente, no de lo superfluo" "55. Sinceramente discordamos de tal posición. No existe diferencia alguna de naturaleza entre un bien destinado al uso superfluo y uno destinado al consumo necesario, ni la facultad de apropiación del hombre se extingue una vez satisfechas sus necesidades fundamentales. Lo adquirido como fruto del trabajo sigue siendo la consecuencia de algo tan propio del hombre como sus actos, sin que se vea razón alguna para poner un límite cuando se han satisfecho las necesidades urgentes. No se ve tampoco manera de conciliar tal posición con el dominio de los bienes de producción, ni con la institución de la herencia.

Dicha doctrina resulta, además, incompatible con los muchos textos pontificios que reconocen la desigualdad de fuerzas naturales del cuerpo y del espíritu, la que existe también en la posesión de bienes. Es justo que haya limitaciones al dominio, y que la autoridad intervenga para corregir los abusos y paliar las desigualdades excesivas. Pero deducir de ello que el derecho natural de propiedad se extingue en cuanto tal una vez satisfecho un cíerto margen de necesidades, cuya determinación por otra parte es muy difícil, es ir demasiado lejos. Con los argumentos y citas ya expuestos podríamos dar por refutada esta tesis, pero dado el apoyo publicitario que hasta hace no muchos años ha recibido y el confusionismo que ella entraña, la abordaremos con más detalle. De suyo, deberiamos analizarla de inmediato, pero esperamos mostrar con claridad de dónde procede tal error, en una próxima ocasión, al estudiar lo relativo al uso común de los bienes.

${ }^{54}$ No 109.

${ }^{\circ} \mathrm{G}$. Renard, Propriété privée et propriété humaine (Paris, 1925) ; E. G. Renard et L. Trotabas. La fonction sociale de la propriétè (Paris, 1930). 


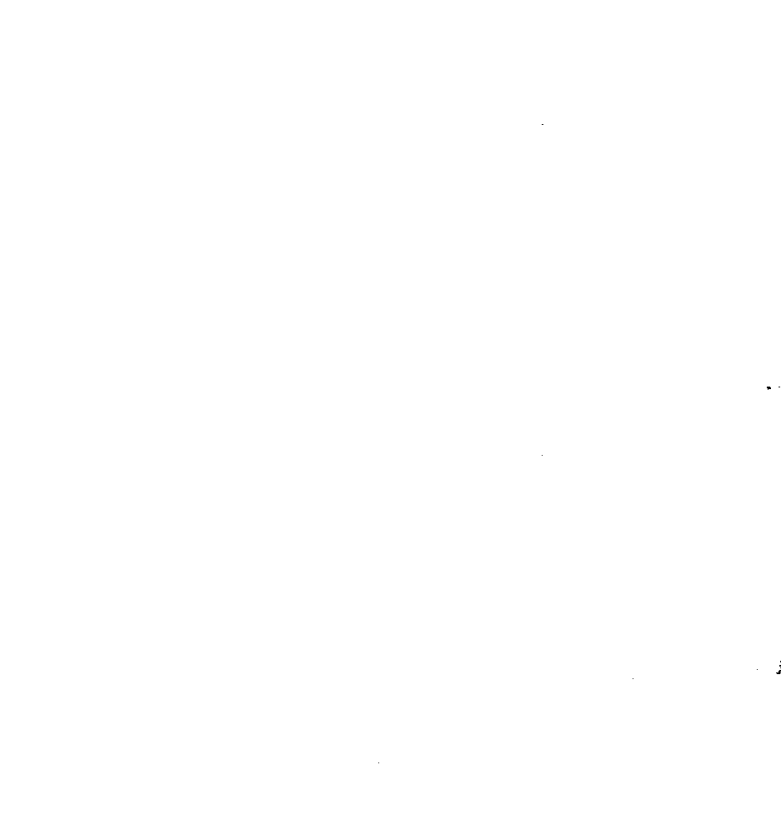

